\title{
SUCCESSION AND GROWTH STRATEGY OF A SPRING MICROBIAL COMMUNITY FROM KEZHOU SINTER IN CHINA
}

\author{
Hongmei Yang; Kai Lou*
}

Institute of Microbiology, Xinjiang Academy of Agricultural Sciences, 403 Nanchang Road, Urumqi, Xinjiang 830091, China.

Submitted: December 30, 2009; Returned to authors for corrections: April 06, 2010; Approved: June 21, 2010.

\begin{abstract}
The succession and growth strategy of a spring microbial community under earthquake action were investigated. The majority of pre-earthquake isolates belonged to the Gammaproteobacteria, including two numerically dominant Stenotrophomonas sp. RB25 and Acinetobacter sp. RB11 (r-strategists). The predominant post-earthquake isolates were Alphaproteobacteria, with Rhizobium sp. RA42 (K-strategists) being dominant among these organisms.
\end{abstract}

Key words: Growth strategy, Succession, Spring microbe, Earthquake

The $\mathrm{r}$ - and K-selection theory is a popular ecological theory developed by MacArthur and Wilson (12). Andrews and Harris (1) provided a framework to apply the terms of $\mathrm{r}$ - and $\mathrm{K}$ selection to microbial community succession. In $\mathrm{r} / \mathrm{K}$ selection theory, it is proposed that as communities develop, r-selected species (r-strategists) with investment of energy mainly in reproduction will be replaced by K-selected species (Kstrategists) with relatively higher energy in maintenance and lower energy demands. This concept has been widely used to analyse microbial communities in different successional stages in various environments such as wheat roots and soil (3), lake water (19), glacial soil (15), brown coal colliery substrate (11) and flooded paddy soil (14).

Spring water, which is one of the most active parts of the earth's crust, can actually and sensitively reflect the stress in the crust. Accordingly, analyses of spring parameters including carbon isotope (17), chemical component (4), discharge rate (6) and dissolved gas (18) have been widely conducted to determine if they reflect earthquake activity. However, little information regarding the variations and responses of spring microbial communities and their life strategies under earthquake action has been reported to date.

Xinjiang is a typical inland seismic activity area in China, and the seismic activities in this area are widely distributed along the Altai Mountains, Tianshan Mountains and Kunlun

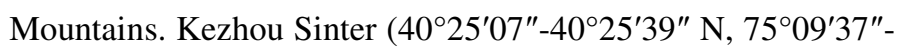
$\left.75^{\circ} 09^{\prime} 58^{\prime \prime} \mathrm{E}\right)$ lies in the linkage of the Tianshan Mountains and Kunlun Mountains in Wuqia County of Xinjiang, which is an earthquake-prone area. Kezhou Sinter is a very infrequent karst landform that is closely related to spring water. This study is the first report to examine the spring microbial communities in the pre- and post-earthquake stages of Kezhou sinter by using culturability, colony-forming curve (CFC) (9) analysis and rand K-selection theory. Our objectives were to investigate spring microbial community succession and their life strategies under earthquake action and to provide a preliminarily assessment of the responses of the spring microbial population in Kezhou sinter to earthquakes, which will provide a certain scientific and theoretical basis for protecting the fragile karst ecosystem. 
On 5 October 2008, Wuqia Ms 6.9 earthquake occurred in an annual earthquake risk region of Wuqia in Xinjiang, approximately $146 \mathrm{~km}$ from our sampling site. The sampling site $\left(40^{\circ} 25^{\prime} 30^{\prime \prime} \mathrm{N}, 75^{\circ} 09^{\prime} 58^{\prime \prime} \mathrm{E}\right)$ is the largest spring of Kezhou Sinter, where the spring water flows approximately $46 \mathrm{~m}$ before discharging into a nearby creek. The water samples were collected on 4 October 2008 (pre-earthquake) and 15 October 2008 (post-earthquake), respectively. Triplicate integrated water samples (top 10-15 cm) were collected in two 5-liter sterile plastic tanks from the pre- and post-earthquake spring, respectively, and stored at $4^{\circ} \mathrm{C}$ until processing. The numbers of cultured cells were determined by spreading $200 \mu \mathrm{l}$ aliquots of samples that were serially diluted $10^{0}-10^{-3}$ onto plates containing R2A agar (13). The plates were incubated for up to 30 days at $20^{\circ} \mathrm{C}(2,7,20)$. A colony-forming curve was generated for each sample by counting newly visible colonies every day for a 30-day incubation period. Fast growers (rstrategists) were defined as bacteria that produced visible colonies at $20^{\circ} \mathrm{C}$ on $\mathrm{R} 2 \mathrm{~A}$ medium within 3 days (11). Total cultured microbial counts obtained were expressed in colony forming units (cfu) per milliliter of sample. Differences in the cfu counts between the pre- and post-earthquake stages were evaluated by two-way analysis of variance (ANOVA) followed by Duncan's multiple range test (Duncan). Values were considered to be significant at the $95 \%$ and $99 \%$ confidence level. All analyses were conducted using the SPSS 13.0 software package.

Colonies grown on plates of the terminal positive dilutions steps were selected based on size, color, form, margin, and surface, after which they were transferred to R2A agar media for further purification. DNA was extracted from purified isolates using the method described by Kim et al. (10), and PCR of the 16S rRNA gene was conducted using the $27 \mathrm{f}$ and 1492r primers (8). All 16S rRNA gene sequences were analyzed and compared to sequences within the NCBI database. The phylogenetic tree was constructed by NeighborJoining method with the MAGA 4.0 software package (16).

Significant differences were found in the CFCs of the preand post-earthquake microbial populations (Figure1). The culturable bacteria counts significantly lower $(p<0.01)$ after the earthquake. The colonies were observed after 1 day of incubation, regardless of the successional stage, and no colonies appeared after about 12 days of incubation. The preearthquake stage was dominated by fast growers (r-strategists) that could rapidly colonize the media $(63.88 \%$ of the total microbial colonies formed in the first $3 \mathrm{~d}$ ). In post-earthquake samples, only $25.64 \%$ of the microbial population could be characterized as fast growers, and most colonies required 4-12 days to become visible. These results supported the conclusions of Sigler et al. (15), who found that there was an apparent shift from $\mathrm{r}$ - to $\mathrm{K}$-strategists with successional age. Based on the concept of $\mathrm{r} / \mathrm{K}$ strategists, competition and natural selection should favor K-selection $(1,12)$. The results of this study suggested that earthquakes promote competition and result in higher percentages of K-strategists. K-strategists are presumably more efficient users of environmental resources that would be more competitive in such an environment.

Overall, 52 CFU (25 from the pre-earthquake spring and 27 from the post-earthquake spring) were selected from the terminal positive dilution steps for analysis. Representative sequences have been assigned GenBank accession numbers FJ898291 to FJ898300 and FJ898302 to FJ898320 (Figure 2). Phylogenetic analysis of the bacterial 16S rDNA gene sequences showed that all isolates fell into one of the following six following bacterial lineages: Alphaproteobacteria, Actinobacteria, Bacteroidetes, Deinococcus-Thermus, Firmicutes and Gammaproteobacteria. Members of the phylum Bacteroidetes were only obtained from spring water collected post-earthquake. The genera Lysobacter, Nocardiopsis, Stenotrophomonas and Streptomyces were no longer present after the earthquake, while Aeromonas, Arthrobacter, Flavobacterium, Kocuria, Mycetocola, Pedobacter, Planomicrobium, Rothia and Staphylococcus only appeared during the post-earthquake stage. The majority of pre-earthquake isolates were affiliated with the Gammaproteobacteria $(82.63 \%$ of the total microbial colonies), including two numerically dominant Stenotrophomonas sp. RB25 and Acinetobacter sp. RB11 (r- 
strategists, $56.86 \%$ and $24.31 \%$ of the total microbial colonies, respectively), which disappeared after the earthquake. The predominant groups among the post-earthquake isolates were Alphaproteobacteria (49.64\% of the total microbial colonies), including the most numerically dominant organism, Rhizobium sp. RA42 (K-strategist, $28.21 \%$ of the total microbial colonies). Strains Stenotrophomonas sp. RB25, Acinetobacter sp. RB11 and Rhizobium sp. RA42 are likely to be as indicator strains during the pre- and post-earthquake period in Kezhou of Xinjiang, China.

Culturability and colony-forming curve analyses revealed that the pre- and post -earthquake spring microbial community structure and growth strategy in Kezhou sinter differed obviously. This finding may have been due to a change in the physical-chemical properties in spring water and consequent change in the microbial community in this relatively stable karst ecosystem (5) after the earthquake. This variation may reflect the response of microbial populations to the earthquake to some extent. However, because of the comprehensive influence of geographical conditions and climatic factors etc., Kezhou sinter is constantly at motion and changing during the evolutionary process. It should be noted that this study only involved two samples, therefore, it only provide a preliminarily assessment of the responses of the spring microbial population in Kezhou sinter to earthquakes. Further work involving continuous collection and monitoring of spring water samples is necessary to determine the long-term variability of microbial communities, which will enable a more exact and accurate evaluation of the relationship between earthquake activities and spring microbial populations.

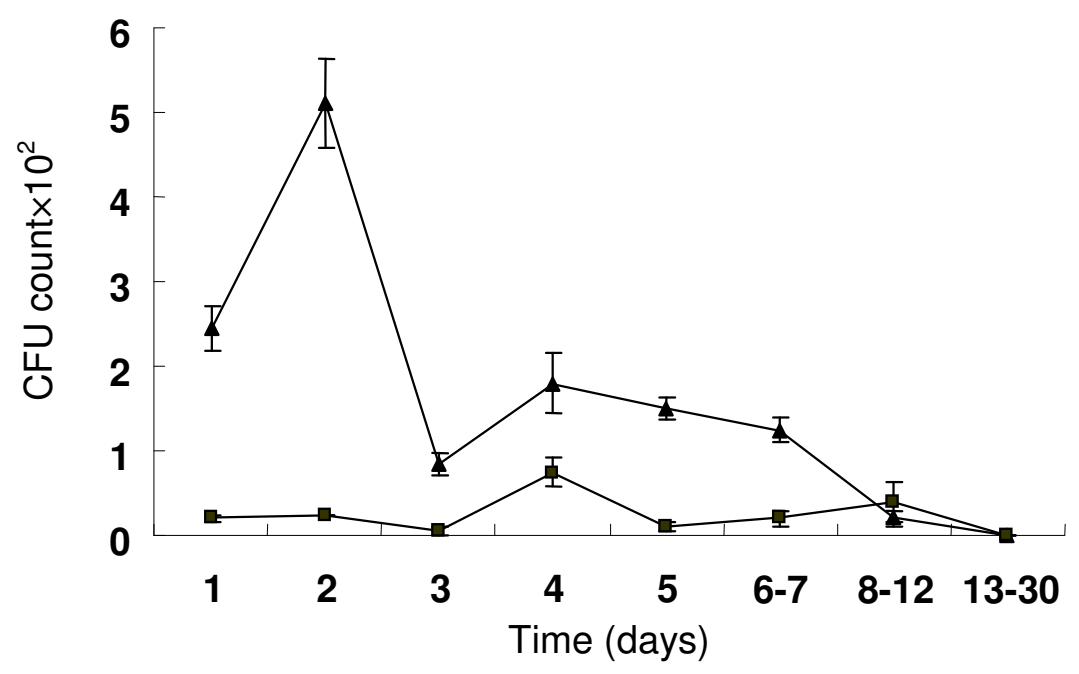

Figure 1. Colony-forming curves (CFCs) of the spring microbial population $\boldsymbol{\Delta}$ pre-earthquake and $\boldsymbol{\bullet}$ post-earthquake. Colonyforming curves were calculated using the cfu counts of plates that contained 30-300 colonies. Error bars represent the standard deviations among three replicates. 


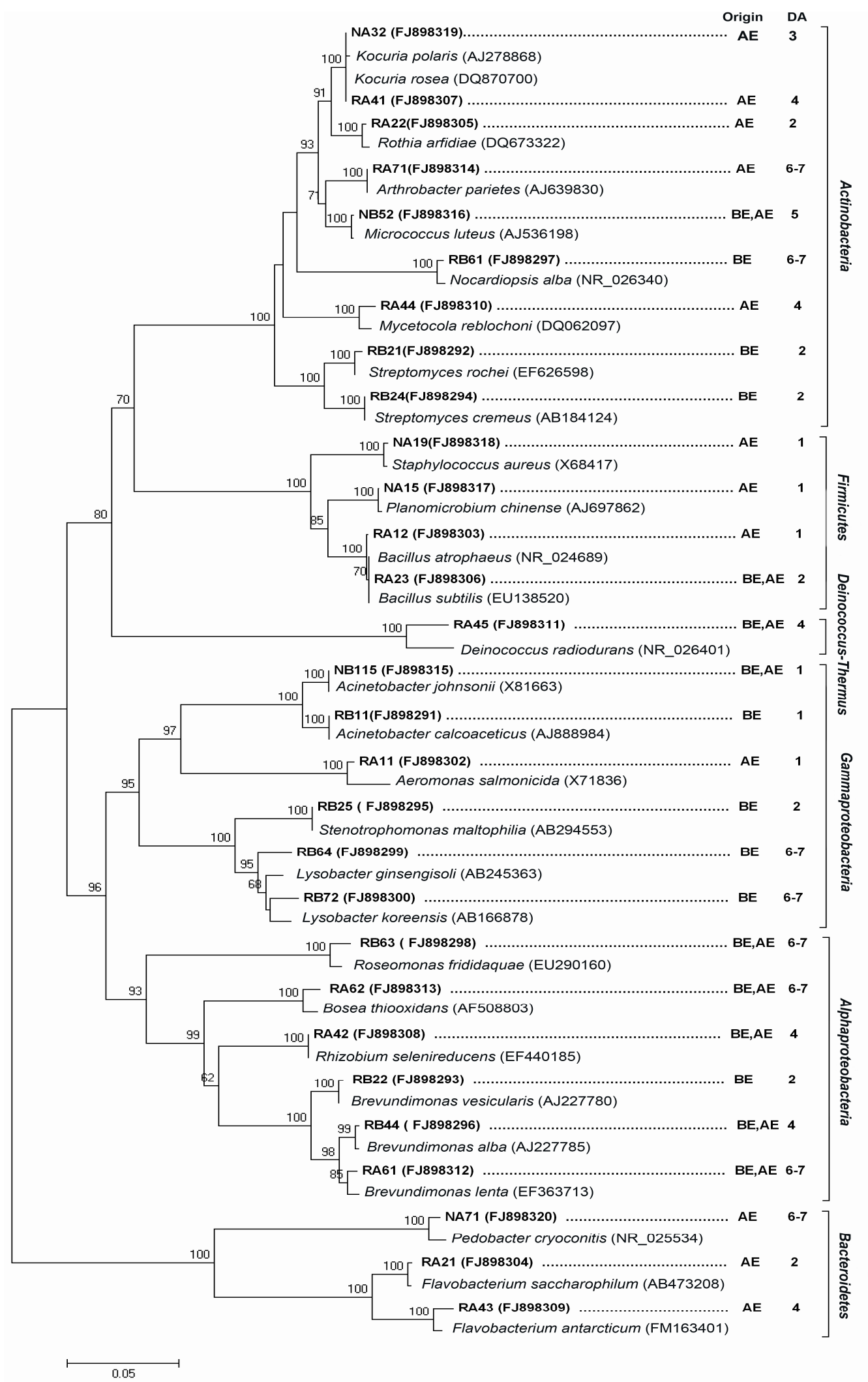

Figure 2. Neighbor-joining tree showing the phylogenetic relationship of microbial $16 \mathrm{~S}$ rRNA gene sequences of isolates obtained from the Kezhou sinter spring in China. The 16S rRNA gene sequence accession numbers of the sequences occur after the species names or strain designation. The capital letters in the left column indicate the sampling origins of the isolates (Origin; "BE" indicates before earthquake and "AE" indicates after earthquake), and the numbers in the right column indicate the day of colony appearance (DA). 


\section{ACKNOWLEDGMENTS}

This work was supported by the Open Project Program of the Specific Habitat Microorganisms Laboratory of Xinjiang (Grant No.XJYS0203-2008-05), and by the 973 Pre-research Program of China (Grant No.2008CB417214). We thank OTKUR Mahmut for samples collection.

\section{REFERENCES}

1. Andrews, J.H.; Harris, R.F. (1986). r- and K-selection and microbial ecology. Adv. Microb. Ecol. 9, 99-147.

2. Bugno, A.; Almodovar, A.A.B.; Pereira, T.C. (2010). Enumeration of heterotrophic bacteria in water for dialysis: comparison of the efficiency of Reasoner'2 agar and plate count agar. Braz. J. Microbiol. 41, 15-18.

3. De Leij F.A.A.M.; Whipps, J.M.; Lynch, J.M. (1993). The use of colony development for the characterization of bacterial communities in soil and on roots. Microb. Ecol. 27, 81-97.

4. Dilixiati, K., Zhu, C.Y. (2008). Study on precursor anomalous characteristics of hydrochemistry in new No.10 spring before strong earthquakes. Inland. Earthq (China). 22, 90- 96.

5. Farnleitner, A.H.; Wilhartitz, I.; Ryzinska, G.; Kirschner, A.K.T.; Stadler, H.; Burtscher, M.; Hornek, R.; Szewzyk, U.; Herndl, G.; Mach, R.L. (2005). Bacterial dynamics in spring water of alpine karst aquifers indicates the presence of stable autochthonous microbial endokarst communities. Environ. Microbiol. 7, 1248-1259.

6. Gao, X.Q.; Xu, Q.L.; Li Y.P.; Li, X.Y.; Zhang, X.M.; Cui, Y. (2001). Reflecting earthquake analysis of discharge rate for the No 10 spring spot in Urumqi. J. Seismol. Res (China). 24, 233-237.

7. Gonzalez, A.M.; Paranhos, R.; Lutterbach, M.S. (2006). Heterotrophic bacteria abundances in Rodrigo de Freitas Lagoon (Rio de Janeiro, Brazil). Braz. J. Microbiol. 37, 428-433.

8. Gurtler, V.; Stanisich,V. A. (1996). New approaches to typing and identification of bacteria using the $16 \mathrm{~S}-23 \mathrm{~S}$ rDNA spacer region. Microbiology. 142, 3-16.
9. Hashimoto, T.; Hattori, T. (1989). Grouping of soil bacteria by analysis of colony formation on agar plates. Biol. Fertil. Soils. 7, 198-201.

10. Kim, S.B.; Yoon, J.H.; Kim,H.; Lee, S.T.; Park, Y.H.; Goodfellow, M. (1995) A phylogenetic analysis of the genus Saccharomonospora conducted with 16S rRNA gene sequences. Int. J. Syst. Bacterio. 45, 351 356.

11. Kristufek, V.; Elhottova, D.; Chronakova, A.; Dostalkova, I.; Picek, T.; Kalcik, J. (2005). Growth strategy of heterotrophic bacterial population along successional sequence on spoil of brown coal colliery substrate. Folia. Microbiol. 50, 427-435.

12. MacArthur, R.H.; Wilson, E.O. (1967). The theory of island biogeography. Princeton University Press, Princeton, NJ.

13. Reasoner, D.J.; Geldreich, E.E. (1985). A new medium for the enumeration and subculture of bacteria from potable water. Appl. Environ. Microbiol. 49, 1-7.

14. Shrestha, P.M.; Noll, M.; Liesack, W. (2007). Phylogenetic identity, growth-response time and rRNA operon copy number of soil bacteria indicate different stages of community succession. Microb. Ecol. 9, 24642474.

15. Sigler, W.V.; Zeyer, J. (2004). Colony-forming analysis of bacterial community succession in deglaciated soils indicates pioneer stresstolerant opportunists. Microb. Ecol. 48, 316-323.

16. Tamura, K.; Dudley, J.; Nei, M.; Kumar, S. (2007). MEGA 4: Molecular evolutionary genetics analysis (MEGA) software version 4.0. Mol. Biol. Evol. 24, 1596-1599.

17. Wang, D.; Xu, Q.L.; Yushupov, SH.S. (2002). Preliminary study on carbon isotope in groundwater on Tianshan seismic activity area. Inland. Earthq (China). 16, 294 -301.

18. Wang, X.; Zhao, X.M.; He, C.J. (2006). Precursory anomalies of subsurface fluid before Jiangyang earthquake and Baoji earthquake at the Lingtong seismic station. J. Catastrophology (China). 21, 64-68.

19. Weinbauer, M.G.; Höfle, M.G. (1998). Distribution and life strategies of two bacterial populations in a eutrophic lake. Appl. Environ. Microbiol. 64, 3376-3783

20. Williams, H.N.; Quinby, H.; Romberg, E. (1994). Evaluation and use of low nutrient medium and reduced incubation temperature to study bacterial contamination in the water supply of dental units. Can. J. Microbiol. 40, 127-131. 